\title{
(6) OPEN ACCESS \\ The importance of tissue handling of surgically removed breast cancer for an accurate assessment of the Ki-67 index
}

\author{
Nobuyuki Arima, ${ }^{1}$ Reiki Nishimura, ${ }^{2}$ Tomofumi Osako, ${ }^{2}$ Yasuyuki Nishiyama, ${ }^{2}$ \\ Mamiko Fujisue, ${ }^{2}$ Yasuhiro Okumura, ${ }^{3}$ Masahiro Nakano, ${ }^{3}$ Rumiko Tashima, ${ }^{4}$ \\ Yasuo Toyozumi ${ }^{5}$
}

'Department of Pathology, Kumamoto Shinto General Hospital, Kumamoto, Japan ${ }^{2}$ Department of Breast Oncology, Kumamoto Shinto General Hospital, Kumamoto, Japan

${ }^{3}$ Department of Breast \& Endocrine Surgery, Kumamoto City Hospital, Kumamoto, Japan

${ }^{4}$ Department of Surgery, Kumamoto City Hospital, Kumamoto, Japan ${ }^{5}$ Department of Pathology, Kumamoto City Hospital, Kumamoto, Japan

\section{Correspondence to}

Dr Nobuyuki Arima, Department of Pathology, Kumamoto Shinto Genera Hospital, 1-17-27 Shinyashiki, Chuo-ku, Kumamoto 862-8655, Japan; nobuari0816@yahoo.co.jp

Received 2 June 2015 Revised 22 August 2015 Accepted 27 August 2015 Published Online First 29 September 2015

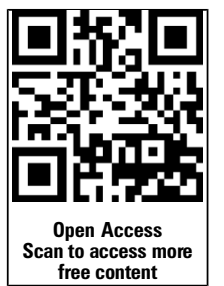

CrossMark

To cite: Arima $\mathrm{N}$, Nishimura R, Osako T, et al. J Clin Pathol 2016;69: 255-259.

\section{ABSTRACT}

Aim Insufficient attention for the Ki-67 immunohistochemistry has been given to the importance of tissue handling for surgical breast cancer specimens. We sought to investigate the effect of fixation status on the Ki-67.

Methods We examined the effect of fixative, time to and duration of fixation using surgical specimens, and finally, compared the paired Ki-67 index in the tumour between core needle and surgical specimen.

Results The Ki-67 was significantly higher when 10\% neutral buffered formalin was used ( $p=0.0276)$. Insufficient fixation caused a drastic reduction in the Ki-67 index $(p=0.0177)$, but not significant in oestrogen receptor (ER) and human epidermal growth factor receptor 2 (HER2). Sixteen hours delayed time to fixation also caused a reduction of the Ki-67 ( $p=0.0284)$, but not significant in ER. Prolonged fixation significantly led to a gradual reduction in the Ki-67 in a time-dependent manner, but not in both ER and HER2. Finally, cutting the tumour before fixation improved fixation status and consequently caused an increased level of the Ki-67 index $(p=0.0181)$, which resulted in a strong correlation of the Ki-67 between core needle and surgical specimen $(r=0.8595)$.

Conclusions Tissue handling of surgical specimen is critical for assessing the Ki-67 compared with ER and HER2. We should pay more attention to tissue fixation status for the standard assessment of the Ki-67 index.

\section{INTRODUCTION}

The Ki-67 is a proliferative cell marker that is expressed in all phases of the cell cycle except the G0 stage. ${ }^{1}$ It has generally been used as a way to determine the malignant potential of a tumour and as a prognostic marker in patients with malignant neoplasms (brain tumours, gastrointestinal and pancreatic neuroendocrine tumours, lymphomas and breast cancers). ${ }^{2-6}$ Patients with human epidermal growth factor receptor 2 (HER2)-negative luminal type breast cancer with higher cell proliferation demonstrated more unfavourable prognosis compared with those with lower cell proliferation..$^{7-10}$ Therefore, the 2011 and 2013 St. Gallen's international consensus meeting recommended chemotherapy in addition to hormone therapy for HER2-negative luminal-type breast cancer with higher Ki-67 index. ${ }^{11}{ }^{12}$ However, a standard assessment of the Ki-67 index has not yet been established, and the most recent studies have only focused on interobserver variability in the interpretation of these values. ${ }^{13-15}$

The American Society of Clinical Oncology (ASCO)/the College of American Pathologists (CAP) guidelines recommend proper tissue handling for hormone receptors (oestrogen receptor (ER) and PgR) and HER2, ${ }^{16-18}$ but insufficient attention has been given to the importance of tissue handling for the Ki-67 index. The only mention to this effect was presented in a review article by Dowsett et al, who suggested that the pre-analytical setting is a potential factor that might affect the Ki-67 immunohistochemistry (IHC). ${ }^{9}$ Formerly, we evaluated the Ki-67 index of surgically removed cancers using slides prepared at several different institutes. The analysis revealed that there were many cases with extremely low or with a diminished level of the Ki-67 protein even in tumour cells with a high grade. This led to the hypothesis that postoperative tissue handling of surgically removed breast cancer might strongly affect the Ki-67 index.

Postoperative tissue handling of surgical specimens that might affect IHC includes the size of the specimen, time to fixation from tumour removal, type of fixative and duration of fixation, and the effects of these factors on several biomarkers have been studied. ${ }^{19-27}$ However, rigorous analysis on the importance of tissue handling for the Ki-67 protein has not yet been performed. Therefore, we thoroughly examined the various fixation conditions of surgically removed breast cancer tissue and their effects on the Ki-67 index.

\section{MATERIALS AND METHODS}

Materials, histological examination and IHC

Surgically removed breast cancer tissue in cases with either conservative resection or mastectomy at Kumamoto City Hospital were used in this study. Histopathological examination was routinely performed using formalin fixed paraffin embedded (FFPE) tissue. The antibody used for IHC was Ki-67 (clone MIB-1, mouse monoclonal, Dako, Glostrup, Denmark), HER2 (clone 4B5, rabbit monoclonal, Roche Diagnostics, Tokyo, Japan) and ER (clone SP1, rabbit monoclonal, Roche Diagnostics). IHC was performed using BENCHMARK XT (Ventana, Tucson, USA), and the details for this procedure can be found in the two articles published by Nishimura et al in $2010 .^{6} 9$ The Ki-67 index was determined by 
calculating the proportion of positive-nuclear staining cells in the hot spot (at least 500 cells). ER expression was calculated as the percentage of positive cancer cells. The staining pattern of HER2 (invasive cancer cells) was divided into the following four groups: $3+$ (strong and diffuse), $2+$ (moderate and diffuse), $1+$ (focal and weak) and 0 (negative). ${ }^{16}$ Assessment of IHC was performed by two specialised pathologists.

\section{Type of fixative}

The surgically removed breast cancer tissue of 1310 patients from June 2009 to June 2013 was used in this study. Cancer tissues in the first group $(n=655)$ were fixed with $10 \%$ neutral buffered formalin (NBF) for the last two years, while those in the second group $(n=655)$ were fixed with $15 \%$ unbuffered formalin for the first two years. The Ki-67 index between the two groups was then evaluated and compared. Time to fixation from tumour removal, duration of fixation and the preparation of the FFPE and IHC methods were identical for the two groups.

\section{Time of fixation}

Time to fixation from tumour removal

Samples of fresh tumour sliced from surgically removed cancer tissue were prepared and stored for a duration period of 1-16 h before formalin fixation. These tissues were wrapped with polyethylene film at room temperature to avoid dehydration. Biomarker expression was evaluated by using IHC slides when the sliced tumour tissue reached the designated cold ischaemia time.

\section{Time of fixation \\ Insufficient fixation}

Samples of fresh tumour sliced from a surgically removed breast cancer were prepared and fixed with formalin followed by the preparation of the FFPE tissue. A comparison of the biomarker expression was then made between tumours with an insufficient fixation period $(3 \mathrm{~h})$ and those with a full fixation period $(48 \mathrm{~h})$.

\section{Prolonged fixation}

Samples of fresh tumour derived from the same removed breast cancer were prepared and fixed with formalin for a designated duration time (from $48 \mathrm{~h}$ to 90 days), followed by the preparation of the FFPE tissues. Expression of biomarkers was then analysed using IHC. The same procedure was used for each of the samples other than duration of fixation.

\section{Effect of cutting the centre of a fresh tumour just before fixation}

The surgically removed breast cancer tissue of 1190 patients from March 2009 to November 2011 was used. For the latter half of this period, the central portion of the surgically removed breast cancer was cut just before fixation in the first group $(n=594)$ in order to promote formalin penetration into the tumour tissue more quickly. The tumours in the second group (control group, $n=594$ ) were not pretreated in the first half of this period. The Ki-67 index between the two groups was then evaluated and compared.

\section{Comparison between core needle biopsy and surgically removed cancer tissue}

The cancer tissue of 136 patients in which core needle biopsy was performed before surgical resection was used. Neoadjuvant cases were excluded. Core needle tissues were fixed for $6-48 \mathrm{~h}$ and the surgically removed tissues were fixed for $48-96 \mathrm{~h}$ after cutting the centre of the tumour just before formalin fixation.
Table 1 Effect of type of fixative on Ki-67 immunohistochemistry

\begin{tabular}{llll}
\hline $\begin{array}{l}\text { Type of } \\
\text { fixative }\end{array}$ & $\begin{array}{l}\text { No. of } \\
\text { samples }\end{array}$ & $\begin{array}{l}\text { Ki-67 index } \\
\text { (mean } \pm \text { SD: \%) }\end{array}$ & $\begin{array}{l}\text { p Value } \\
\text { (Welch's t test) }\end{array}$ \\
\hline $10 \% \mathrm{NBF}$ & 655 & $30.5 \pm 22.9$ & 0.0276 \\
$15 \% \mathrm{~F}$ & 655 & $27.8 \pm 20.9$ & \\
\hline
\end{tabular}

$10 \%$ NBF, $10 \%$ neutral buffered formalin; $15 \% \mathrm{~F}, 15 \%$ unbuffered formalin.

The Ki-67 index in each of the 136 pairs of core needle and surgically removed cancer tissue was analysed.

\section{Statistical analysis}

Unpaired t test was used to compare the mean $\mathrm{Ki}-67$ index for type of fixative (Welch's t test) and the effect of tumour cutting analyses (Student's t test). Paired t test was used to compare the mean Ki-67 index and the mean percentage of ER-positive cancer cells for time to fixation, insufficient fixation and prolonged fixation assays. The Pearson's correlation coefficient was used to analyse the relationship between the Ki-67 index in the core needle tissue and the surgically removed breast tissue.

\section{RESULTS}

\section{Type of fixative}

The mean Ki-67 index in cancers fixed with 10\% NBF was $30.5 \% \pm 22.9 \%$, and the mean Ki-67 index in cancers fixed with $15 \%$ unbuffered formalin was $27.8 \% \pm 20.9 \%$. The results revealed that there was a significant difference $(p=0.0276)$ in the Ki-67 index between the two different types of fixatives (table 1).

\section{Time to fixation}

Sixteen hours delayed time to fixation caused a significant reduction of the Ki-67 index $(\mathrm{p}=0.0284$, table 2$)$, but not in ER expression $(p=0.3129$, table 3$)$, although $<10 \mathrm{~h}$ delayed time to fixation did not reveal a recognisable influence on the Ki-67 and ER expression (data not shown).

\section{Time of fixation}

Insufficient fixation

Insufficient fixation caused a significant reduction of the Ki-67 index $(p=0.0177)$ and the percentage of ER-positive cells $(p=0.0364)$, although the reduction of the Ki-67 index was more drastic compared with ER (tables 2 and 3). In an HER2-positive breast cancer, a serious reduction in the Ki-67 index (from $33 \%$ to $5 \%$ ) was observed in the insufficient

Table 2 Effect of time of fixation on Ki-67 immunohistochemistry

\begin{tabular}{llll}
\hline Conditions & $\begin{array}{l}\text { No. of } \\
\text { samples }\end{array}$ & $\begin{array}{l}\text { Ki-67 index } \\
\text { (mean } \pm \text { SD: \%) }\end{array}$ & $\begin{array}{l}\text { p Value } \\
\text { (paired t test) }\end{array}$ \\
\hline $\begin{array}{l}\text { Time to fixation } \\
\text { Immediate }\end{array}$ & 10 & $43.1 \pm 11.5$ & 0.0284 \\
$\begin{array}{l}16 \mathrm{~h} \\
\text { Insufficient fixation }\end{array}$ & & $36.7 \pm 18.4$ & \\
$48 \mathrm{~h}$ & 8 & $21.8 \pm 10.8$ & 0.0177 \\
$3 \mathrm{~h}$ & & $8.8 \pm 9.4$ & \\
$\begin{array}{l}\text { Prolonged fixation } \\
48 \mathrm{~h}\end{array}$ & 10 & $36.3 \pm 13.6$ & \\
14 days & & $26.6 \pm 15.8$ & 0.0414 \\
28 days & & $22.4 \pm 11.2$ & 0.0042 \\
56 days & & $14.4 \pm 6.5$ & 0.0003 \\
\hline
\end{tabular}


Table 3 Effect of time of fixation on oestrogen receptor (ER) immunohistochemistry

\begin{tabular}{llll}
\hline $\begin{array}{l}\text { Conditions } \\
\text { samples }\end{array}$ & $\begin{array}{l}\text { ER } \\
\text { (mean } \pm \text { SD: } \%)\end{array}$ & $\begin{array}{l}\text { p Value } \\
\text { (paired t test) }\end{array}$ \\
\hline $\begin{array}{l}\text { Time to fixation } \\
\text { Immediate }\end{array}$ & 4 & $96.8 \pm 4.50$ & 0.3129 \\
$\begin{array}{l}16 \mathrm{~h} \\
\text { Insufficient fixation }\end{array}$ & & $89.5 \pm 16.4$ & \\
$\begin{array}{l}48 \mathrm{~h} \\
3 \mathrm{~h}\end{array}$ & 8 & $87.1 \pm 25.3$ & 0.0364 \\
$\begin{array}{l}\text { Prolonged fixation } \\
48 \mathrm{~h}\end{array}$ & & $66.1 \pm 34.6$ & \\
14 days & 10 & & \\
28 days & & $95.8 \pm 4.3$ & vs $48 \mathrm{~h}$ \\
56 days & & $88.3 \pm 12.6$ & 0.2152 \\
& & $84.5 \pm 18.6$ & 0.2665 \\
\hline
\end{tabular}

fixation setting (figure 1A, B), but HER2 overexpression remained the same (figure $1 \mathrm{C}, \mathrm{D}$ ).

\section{Prolonged fixation}

The Ki-67 index gradually decreased in a time-dependent manner in ER-positive cancers, and this reduction was significant when tumours with a 2-day-long fixation period was regarded as controls (table 2), while a reduction of ER labelling was not significant (table 3). Figure 2A demonstrated that prolonged fixation caused a gradual reduction of the Ki-67 index in ER-positive cancer cells from $41 \%$ to $17 \%$, but there was no recognisable change in ER labelling in the same tumour even in a 60-day-long fixation period. Similarly, the Ki-67 index visually decreased in a time-dependent manner from $74 \%$ to $13 \%$ in HER2-positive cancer cells, but only a slight decrease in HER2 expression in the same tumour was observed even in a 84-day-long fixation period (figure 2B).

\section{Effect of cutting the centre of the surgically removed breast} tumour just before fixation on the Ki-67 index

There was a significant difference between the average Ki-67 index $(26.2 \% \pm 19.8 \%)$ in tumours in which the centre of fresh

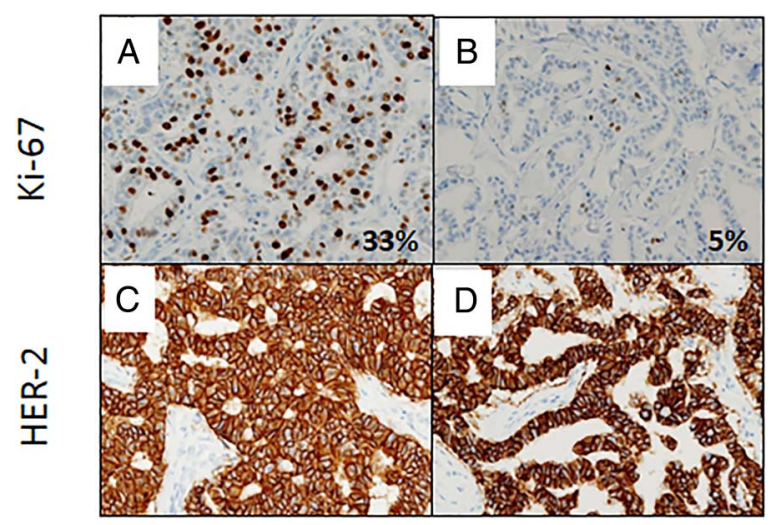

Figure 1 Effect of insufficient fixation on Ki-67 immunohistochemistry (IHC) in human epidermal growth factor receptor 2 (HER2)-positive cancer. Insufficient fixation caused a drastic reduction in the Ki-67 index from $33 \%$ to $5 \%$ in a HER2-positive cancer (A and $B$ ), while there was no significant change in the HER2 expression ( $C$ and $D)$. (A and B) Ki-67 IHC; (C and D) HER2 IHC; (A and C) fixed for $48 \mathrm{~h}$; $(B$ and $D)$ fixed for $3 \mathrm{~h}$.

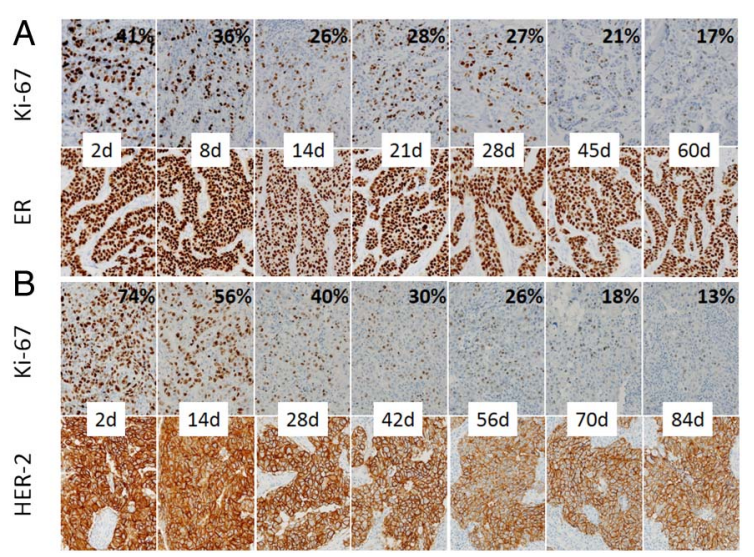

Figure 2 Effect of prolonged fixation on Ki-67 immunohistochemistry in oestrogen receptor (ER)-positive (A) and human epidermal growth factor receptor 2 (HER2)-positive (B) cancer. Prolonged fixation caused a gradual reduction in the Ki-67 index in a time-dependent manner ( $A$ and $B$, top), while there was no significant reduction in both ER ( $A$, bottom) and HER2 (B, bottom) expression.

tumours had been cut just before fixation and the control group $(23.5 \% \pm 18.6 \%)$ in which the centre of fresh tumours had not been cut $(p=0.0181)$ as shown in table 4 .

\section{Comparison of the Ki-67 index between core needle and surgical specimen}

There was a strong correlation (Pearson's correlation coefficient $=0.8595)$ between the Ki-67 index of core needle and the $\mathrm{Ki}-67$ index of surgical specimen in the same tumour (figure 3).

\section{DISCUSSION}

The results in this study clearly demonstrated that proper tissue handling of surgically removed breast cancer tissue was extremely important for a standard assessment of the $\mathrm{Ki}-67$ in contrast to ER or HER2.

Out of several factors related to tissue handling that might influence IHC, insufficient fixation caused a most serious negative effect on the Ki-67 index in proliferating tumour cells, although a mild but significant reduction of the percentage of ER-positive tumour cells was also observed in the same condition. On the other hand, overexpression of HER2 protein (score $3+$ ) was remained unchanged even in this condition. These results suggest that the effect of fixation status on IHC differs in varying degrees depending on the type of biomarker antibody used. In contrast to core needle biopsy, insufficient fixation is more likely to occur in surgically removed tissues when they are inadequately handled after removal. Breast tissue is mainly composed of fat and connective tissue and is often hard to fix with formalin because formalin penetrates tissue at an average rate of $1 \mathrm{~mm} / \mathrm{h} .{ }^{19}$ The result that the $\mathrm{Ki}-67$ index in cases where the centre of the tumour was cut before fixation

Table 4 Effect of cutting the removed tumour before fixation on Ki-67 immunohistochemistry

\begin{tabular}{llll}
\hline Cutting the tumour & $\begin{array}{l}\text { No. of } \\
\text { samples }\end{array}$ & $\begin{array}{l}\text { Ki-67 index } \\
\text { (mean } \pm \text { SD: \%) }\end{array}$ & $\begin{array}{l}\text { p Value } \\
\text { (Student's t test) }\end{array}$ \\
\hline $\begin{array}{l}\text { With cut } \\
\text { Without cut }\end{array}$ & 594 & $26.2 \pm 19.8$ & 0.0181 \\
\hline
\end{tabular}




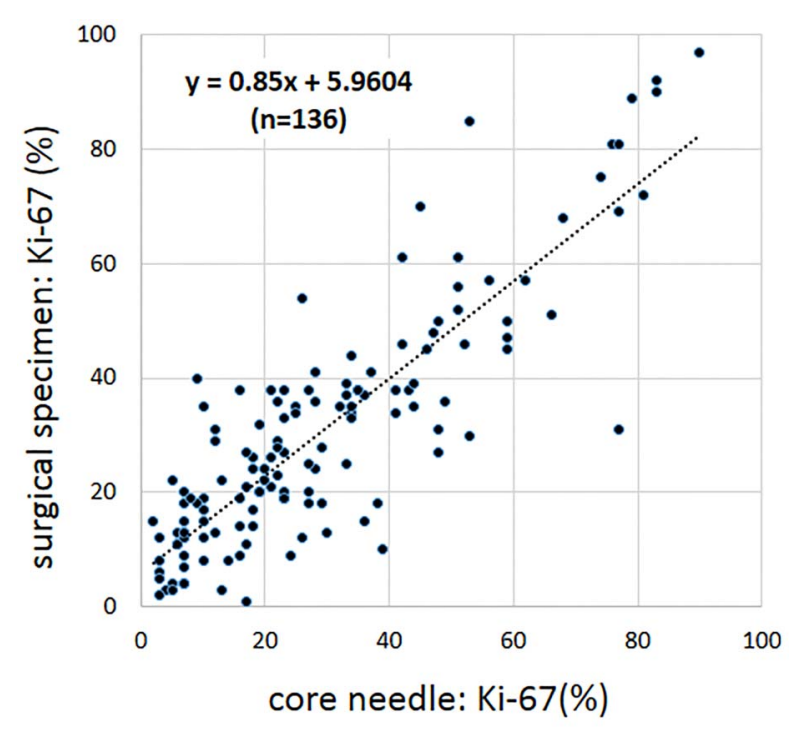

Pearson's correlation coefficient: 0.8595

Figure 3 Comparison of the Ki-67 index between core needle and surgical specimen in the same tumour. The Ki-67 index in each of the 136 pairs of core needle and surgical specimen originating from the same tumour were analysed. The Ki-67 index independently scored were strongly correlated (Pearson's correlation coefficient $=0.8595$ ).

was significantly higher than in cases not pretreated implies that cutting the tumour may reduce the amount of time it takes for formalin to seep into the tumour cells and possibly prevent insufficient fixation. Hewitt $e t a l^{19}$ state that the fixation process entails three elements-thickness of tissue, volume of fixative and time of fixation-and failure to optimise all three of these elements results in underfixation or overfixation of the tissue, both of which result in degradation of the specimen after paraffin infiltration. The ASCO/CAP guideline for hormone receptors and HER2 recommend that samples be sliced at 5-10 $\mathrm{mm}$ intervals after appropriate gross inspection and margins designation. ${ }^{16-18}$ This guideline should be more strictly followed in order to create a standard assessment of the Ki-67 IHC.

Delayed fixation is another problem for increased proteolytic and nucleic acid degeneration in clinical tissue samples. ${ }^{19} 2028$ During both warm ischaemia time (time from the interruption of the blood supply to the tumour by the surgeon to the excision of the tissue specimen) and cold ischaemia time (time from excision to the initiation of tissue fixation), the progressive loss of activity of these molecules can occur after the surgical interruption of blood flow, leading to tissue ischaemia, acidosis and enzymatic degradation. ${ }^{17}$ In our results, although several hours to $<10 \mathrm{~h}$ delayed time to fixation from tumour removal did not cause a recognisable effect on the $\mathrm{Ki}-67$ index as well as the percentage of ER-positive tumour cells, $16 \mathrm{~h}$ delayed time to fixation caused a significant reduction of the Ki-67 index but not the percentage of ER-positive cells. Portier et $a l^{21}$ demonstrated that cold ischaemia time (up to $3 \mathrm{~h}$ ) had no deleterious effect on the detection of HER2 via in situ hybridisation (ISH) or IHC. On the other hand, Khoury et al ${ }^{22}$ indicated that the HER2 fluorescence ISH (FISH) test was particularly vulnerable to cold ischaemia in contrast to ER, PgR and HER2 IHC, and they recommended not to delay formalin fixation for $>1 \mathrm{~h}$. Pinhel et $a l^{23}$ also showed that delayed fixation did not cause a significant reduction in the $\mathrm{Ki}-67, \mathrm{ER}, \mathrm{PgR}$ and HER2 proteins but had an effect on the phosphorylated proteins ( $p$-Akt and p-Erk1/2). Thus, cold ischaemia for several hours is not likely to have a serious effect on ER, PgR, HER2 and Ki-67 IHC but has a negative effect on the HER2 FISH and the some proteins related to signal transduction. Therefore, we should follow the ASCO/CAP guidelines for hormone receptors and HER2, which recommended that removed breast specimens should be fixed as quickly as possible. ${ }^{16-18}$

Prolonged fixation (overfixation) is likely to be less problematic than insufficient fixation (underfixation) but potentially could also lead to false-negative results caused by excessive protein cross-linking by formaldehyde. ${ }^{17}$ In addition, the prolonged exposure of tissue to formalin inhibits the recovery of nucleic acids. ${ }^{19} 24$ In this study, we clearly demonstrated that prolonged fixation caused a significant reduction in the Ki-67-positive cells but not in ER and HER2-positive cells, although Goldstein et $a l^{25}$ and Tong et $a l^{26}$ already indicated that prolonged fixation does not affect ER, PgR and HER2 expression in IHC. Overfixed cancer tissues lead to weak Ki-67 nuclear labelling in a time-dependent manner, which resulted in a disturbance in the detection of Ki-67-positive cells. Furthermore, Selvarajan et $a l^{27}$ showed that HER2 gene amplification detected by FISH is affected by prolonged fixation as well. Thus, prolonged fixation as well as insufficient fixation should be avoided in order to get an accurate Ki-67 index.

The ASCO/CAP guideline for hormone receptors and HER2 recommended $10 \% \mathrm{NBF}^{16-18}$ Formalin-lacking buffer has a limited shelf life and degrades rapidly and the degradation of formalin is believed to contribute to the poor quality of nucleic acids obtained from FFPE tissue. On the other hand, NBF has a longer shelf life and the tissue fixed with NBF yields a consistently better quality RNA. ${ }^{19}$ We showed that cases fixed with $10 \% \mathrm{NBF}$ had a significantly higher Ki-67 index than those fixed with $15 \%$ unbuffered formalin, which indicates that NBF fixation maintain the better quality of not only nucleic acids but also proteins.

Standard fixation times are a minimum of $5 \mathrm{~h}$ for needle and endoscopic biopsy specimens and $\geq 12$ from larger specimens. ${ }^{19}$ Because it is usually harder to affect the fixation status in core needle specimens, it may be the optimal standard for IHC. In contrast, handling surgically removed breast tissue samples is more problematic. In order to prevent insufficient fixation, we should cut the fresh tumour or inject formalin around a tumour using a syringe before fixation. Additionally, comparing the Ki-67 index between core needle biopsy and surgical resection tissue derived from the same tumour seems to be important to evaluate whether or not the surgically removed tissue was

\section{Take home messages}

- Sixteen hours delayed time to fixation caused a significant reduction of the Ki-67 index, but oestrogen receptor (ER) expression was not significantly affected.

- Insufficient fixation caused a drastic and a mild reduction of the Ki-67 index and ER expression, respectively, while human epidermal growth factor receptor 2 (HER2) expression was not affected.

- Prolonged fixation caused a significant reduction of the Ki-67 index, but either ER or HER2 expression was not significantly affected.

- Tissue handling of surgical specimen is more critical for a standard assessment of the Ki-67 compared with ER and HER2. 
suitably handled. Our result in this study demonstrated that the $\mathrm{Ki}-67$ index between these tissues was closely concordant, which indicates that the surgical breast samples were properly handled.

In summary, proper tissue handling is extremely important for an assessment of the Ki-67 index. The first step to standardise the Ki-67 index between laboratories and institutes is to make sure whether the surgical specimens are properly handled.

Handling editor Cheok Soon Lee

Contributors Each of the authors contributed to the manuscript. NA wrote the manuscript. RN, TO, YN, MF, YO, MN, RT and YT made corrections in the manuscript. All authors are responsible for the overall content of the manuscript.

Competing interests None declared.

Patient consent Obtained.

Ethics approval The Ethics Committee of Kumamoto City Hospital.

Provenance and peer review Not commissioned; externally peer reviewed.

Data sharing statement All data in this study are shared by authors, and we do not have additional unpublished data.

Open Access This is an Open Access article distributed in accordance with the Creative Commons Attribution Non Commercial (CC BY-NC 4.0) license, which permits others to distribute, remix, adapt, build upon this work non-commercially, and license their derivative works on different terms, provided the original work is properly cited and the use is non-commercial. See: http://creativecommons.org/ licenses/by-nc/4.0/

\section{REFERENCES}

1 Gerdes J, Lemke $\mathrm{H}$, Baisch $\mathrm{H}$, et al. Cell cycle analysis of a cell proliferationassociated human nuclear antigen defined by the monoclonal antibody Ki-67. Immunol 1984;133:1710-15.

2 Johannessen AL, Torp SH. The clinical value of Ki-67/MIB-1 labeling index in human astrocytomas. Pathol Oncol Res 2006;12:143-7.

3 McKeever PE, Ross DA, Strawderman MS, et al. A comparison of the predictive power for survival in gliomas provided by MIB-1, bromodeoxyuridine and proliferating cell nuclear antigen with histopathologic and clinical parameters. J Neuropathol Exp Neurol 1997:56:798-805.

4 Ekeblad S, Skogseid B, Dunder K, et al. Prognostic factors and survival in 324 patients with pancreatic endocrine tumor treated at a single institution. Clin Cancer Res 2008; 14:7798-803.

5 Kalogeraki A, Tzardi M, Panagiotides I, et al. MIB1 (Ki-67) expression in non-Hodgkin's lymphomas. Anticancer Res 1997;17:487-91.

6 Nishimura R, Osako T, Okumura Y, et al. Clinical significance of Ki-67 in neoadjuvant chemotherapy for primary breast cancer as a predictor for chemosensitivity and for prognosis. Breast Cancer 2010:17:269-75.

7 Criscitiello C, Disaivatore D, Laurentiis MD, et al. High Ki-67 score is indicative of a greater benefit from adjuvant chemotherapy when added to endocrine therapy in Luminal B HER2 negative and node-positive breast cancer. Breast 2014;23:69-75.

8 Cheang MCU, Chia SK, Voduc D, et al. Ki-67 Index, HER2 status, and prognosis of patients with luminal B breast cancer. J Natl Cancer Inst 2009;101:736-50.

9 Nishimura R, Osako T, Okumura Y, et al. Ki-67 as a prognostic marker according to breast cancer subtype and a predictor of recurrence time in primary breast cancer. Exp Ther Med 2010;1:747-54.
10 Feeley LP, Mulligan AM, Pinnaduwage $D$, et al. Distinguishing luminal breast cancer subtypes by Ki67, progesterone receptor or TP53 status provides prognostic information. Mod Pathol 2014;27:554-61.

11 Goldhirsch A, Wood WC, Coates AS, et al. Strategies for subtypes-dealing with the diversity of breast cancer: highlights of the St Gallen international expert consensus on the primary therapy of earle breast cancer 2011. Ann Oncol 2011;22:1736-47.

12 Goldhirsch A, Winer EP, Coates AS, et al. Personalization the treatment of women with early breast cancer: highlights of the St Gallen international expert consensus on the primary therapy of early breast cancer 2013. Ann Oncol 2013;25:1-18.

13 Mikami Y, Ueno T, Yoshimura K, et al. Interobserver concordance of Ki67 labeling index in breast cancer: Japan Breast Cancer Research Group ki67 Ring Study. Cancer Sci 2013;104:1539-43.

14 Polley MY, Leung SC, McShane LM, et al. An International Ki67 Reproducibility Study. J Natl Cancer Inst 2013;105:1897-906.

15 Niikura N, Sakatani T, Arima N, et al. Assessment of the Ki67 labeling index: Japanese validation ring study. Breast Cancer 2014. Published Online First.

16 Wolff AC, Hammond ME, Schwartz JN, et al. American Society of Clinical Oncology/ College of American Pathologists guideline recommendations for human epidermal growth factor receptor 2 testing in breast cancer. J Clin Oncol 2007:25:118-45.

17 Hammond ME, Hayes DF, Dowsett M, et al. American Society of Clinical Oncology/ College of American Pathologists guideline recommendations for immunohistochemical testing of estrogen and progesterone receptors in breast cancer. J Clin Oncol 2010;28:2784-95.

18 Wolff AC, Hammond ME, Hicks DG, et al. American Society of Clinical Oncology; College of American Pathologists. Recommendation for human epidermal growth factor receptor 2 testing in breast cancer: American Society of Clinical Oncology/ College of American Pathologists clinical practice guideline update. J Clin Oncol 2013:31:3997-4013.

19 Hewitt SM, Lewis FA, Cao Y, et al. Tissue handling and specimen preparation in surgical pathology. Arch Pathol Lab Med 2008;132:1929-35.

20 Walker RA. Immunohistochemical markers as predictive tools for breast cancer. J Clin Pathol 2008;61:689-96.

21 Portier BP, Wang Z, Downs-Kelly E, et al. Delay to formalin fixation 'cold ischemia time': effect on ERBB2 detection by in-situ hybridization and immunohistochemistry. Mod Pathol 2013;26:1-9.

22 Khoury T, Sait $\mathrm{S}$, Hwang $H$, et al. Delay to formalin fixation effect on breast biomarkers. Mod Pathol 2009;22;1457-67.

23 Pinhel IF, MacNeill FA, Hills MJ, et al. Extreme loss of immunoreactive $p$-Akt and p-Erk1/2 during routine fixation of primary breast cancer. Breast Cancer Res 2010;12:R76

24 Goldstein NS, Hewitt SM, Taylor CR, et al. Members of Ad-Hoc committee on immunohistochemistry standardization. Recommendations for improved standardization of immunohistochemistry. Appl Immunohistochem Mol Morphol 2007:15:124-33.

25 Goldstein NS, Ferkowicz M, Odish E, et al. Minimum formalin fixation time for consistent estrogen receptor immunohistochemical staining of invasive breast carcinoma. Am J Clin Pathol 2003;120:86-92.

26 Tong LC, Nelson N, Tsourigiannis J, et al. The effect of prolonged fixation on the immunohistochemical evaluation of estrogen receptor, progesterone receptor, and HER2 expression in invasive breast cancer: a prospective study. Am J Surg Pathol 2011;35:545-52.

27 Selvarajan S, Bay BH, Choo A, et al. Effect of fixation period on HER2/neu gene amplification detected by fluorescence in situ hybridization in invasive breast carcinoma. J Histochem Cytochem 2002;50:1963-6.

28 Dowsett M, Nielsen TO, A'Hern R, et al. Assessment of Ki67 in breast cancer: recommendation from the International Ki67 in Breast Cancer working group. J Natl Cancer Inst 2011;103:1656-64. 